\title{
Ortaokul Öğretmenlerinin FeTeMM (Fen-Teknoloji-Mühendislik-Matematik) Farkındalıklarının Farklı Değişkenlere Göre Değerlendirilmesi ${ }^{\star}$ Evaluation of STEM (Science - Technology - Engineering - Mathematics) Awareness of Secondary School Teachers with Various Variables
}

Mustafa ÇEViK ${ }^{* *}$
Arda DANIŞTAY***

\section{Ali YAĞCI ${ }^{* \star * *}$}

\begin{abstract}
Öz. Bu çalışmanın amacı ortaokullarda görevli fen bilimleri, matematik ve bilişim teknolojileri öğretmenlerinin fen - teknoloji - mühendislik - matematik (FeTeMM) eğitimi farkındalıklarının farklı değişkenlere göre değerlendirilmesidir. Yapılan bu araştırma, öğretmenlerin FeTEMM farkındalıklarının doğrudan öğrenilmesine yönelik nicel bir veri aracının kullanıldığı tarama modelinde gerçekleştirilmiştir. Araştırmada seçkisiz olmayan örnekleme yöntemlerinden uygun örnekleme yöntemi benimsenmiştir. Araştırmanın örneklemini, Karaman merkeze bağlı ortaokullarda görev yapan 118 fen, matematik ve bilişim öğretmeni oluşturmuştur. Araştırmada veri toplama aracı olarak Buyruk ve Korkmaz'ın (2016) geliştirmiş oldukları 'FeTeMM Farkındalık Ölçeği' kullanılmıştır. Ölçek katılımcılara uygulandıktan sonra ölçeğin tekrar geçerlik ve güvenirlik çalışmaları yapılmıştır. Olumlu ve olumsuz FeTeMM farkındalığı olmak üzere 2 alt boyuttan oluşan ölçeğin her bir boyutu ile cinsiyet ve branş değişkenleri arasında herhangi bir anlamlılık bulunamamıştır. Ancak mezun olunan fakülte türü, eğitim durumları ve mesleki kıdem değişkenleri ile ölçeğin her iki boyutu arasında anlamlılıklar bulunmuştur. Sonuçta eğitim fakültesi mezunu olan öğretmenler ile genç öğretmenlerin olumlu yönde FeTeMM farkındalığı var iken, mesleki kıdemi fazla olan öğretmenler ve ön lisans mezunu öğretmenlerin olumsuz yönde FeTeMM farkındalıklarının olduğu ortaya çıkmıştır.
\end{abstract}

Anahtar Kelimeler: FeTeMM eğitimi, FeTeMM farkındalığı, ortaokul öğretmenleri.

\begin{abstract}
The aim of this study is to evaluate the awareness of science - technology engineering - mathematics (STEM) education teachers of science, mathematics and information technologies' in secondary schools with different variables. This research is structured with a survey model in which a quantitative data instrument was used to explore awareness of teachers for STEM education. In this study, the convenience / incidental sampling method among non-random sampling methods was adopted. The sample of the study consisted of 118 science, mathematics and information technologies teachers working in secondary schools in the center of Karaman. The 'STEM Awareness Scale' developed by Buyruk and Korkmaz (2016) was used as the data collection tool in this study. The validity and reliability studies were performed again after the scale was applied to the participants. No significant correlation was found between gender and department each dimension of the scale that consists of two sub-dimensions, which are positive and negative STEM awareness. As a result, young teachers and teachers who have graduated from education faculty have a positive STEM awareness while teachers with professional seniority and associate degree graduates have a negative STEM awareness.
\end{abstract}

Keywords: STEM education, STEM awareness, secondary school teachers.
Toplumsal Mesaj. FeTeMM eğitimi son yılların en popüler yaklaşımlarından biridir. Ülkemizde de gittikçe dikkatleri üzerine çeken bu yaklaşımın ortaokul öğretmenlerince farkında olmaları oldukça önemlidir. Çünkü öğretmenlerin FeTeMM yaklaşımı farkındalıkları öğrencilerin 21 yüzyıl becerilerine sahip olarak yetişmelerinde hayatii öneme sahiptir. Bu bağlamda çalışmada ortaokul öğretmenlerin farkındalıkları ve bu farkındalıklarının farklı değişkenlere göre değerlendirilmesi amaçlanmış ve bulgular ortaya konmuştur.

Public Interest Statement. STEM education is one of the most popular approaches in recent years. It is important that secondary school teachers well aware of this apporach, which attracts increasing attention in Turkey. Because teachers' awareness of the STEM approach has a vital importance in training students with 21 st century skills. In this context, it was aimed to reveal awareness of secondary school teachers and evaluate their awareness according to different variables

\footnotetext{
* Bu çalışma 18-21 Mayıs 2017 tarihinde düzenlenen ERPA Uluslararası Eğitim Kongresinde (Budapeşte- 2017) sunulan sözlü bildirinin geliştirilmiş halidir.

${ }^{* *}$ Yrd. Doç. Dr., Karamanoğlu Mehmetbey Üniversitesi, Eğitim Fakültesi, Sınıf Öğretmenliği Bölümü, mustafacevik@kmu.edu.tr *** Öğretmen, simyaturk@hotmail.com

${ }^{* * * *}$ Yüksek Lisans Öğrencisi, ayagci89@gmail.com
} 


\section{GiRiş}

Yaşadığımız yüzyılın özellikle ikinci yarısından sonra bütün alanlardaki ilerlemeler büyük bir ivme kazanmış, özellikle, teknoloji ve fendeki gelişmeler modern hayatın neredeyse bütün alanlarını etkilemiş durumdadır. Globalleşen Dünya'da karşımıza çıkan problemleri aşmak için fen, teknoloji, mühendislik ve matematik gibi birden fazla disiplinin entegrasyonunu gerektirmesi (Moore ve diğerleri, 2014) bu durumun doğal bir sonucudur. Son elli yıldaki bilim ve teknolojideki hızlı ilerlemeler her alana olduğu gibi eğitim alanına da yansımıştır. Özellikle modern çağa uyum sağlayabilme bağlamında ülkelerin eğitim sistemlerinden beklenen; var olan bilgilerle yeni bilgilerin ilişkilendirilmesi, mevcut bilgileri aktarmaktan çok bilgiye ulaşma becerilerinin kazandırılması, bilginin bireyler tarafından yapılandırılması, edinilen bilgilerin günlük hayatta kullanılmasına olanak sağlaması, pratik çözüm yollarının keşfedilmesi gibi temel unsurlardır. Eğitim sistemlerinin temel unsuru öğrencilerin bahsedilen donanımlara sahip olabilmesi çağın gereklerinin farkında olan bilinçli öğretmenler tarafından eğitilmeleri ile mümkündür. Genel olarak öğretmenler öğrencilerin yetiştirilmesinde hiç şüphesiz önemli bir yere sahiptir, özellikle çağın gerekliliklerine uyum sağlamış bireylerin yetiştirilmesinde katkısının azımsanamayacağı şüphesiz olan fen, teknoloji, mühendislik ve matematik alanı öğretmenleridir. Fen-teknoloji-mühendislik-matematik (FeTeMM) disiplinlerinin bütün olarak ele alındığı bu yeni yaklaşım, 21. yüzyıl becerileriyle donanmış, yaratıcı, problem çözme becerilerini sahip, araştıran-sorgulayan, sürdürülebilir kalkınma bilinciyle yaşam boyu öğrenen, bilim okur-yazarı bireylerin yetiştirilmesinde önemli bir yere sahiptir. FeTeMM alanı öğretmenlerinin çă̆ın gereklerine uygun bireyleri yetiştirmek için teknolojik pedagojik alan bilgisine sahip olmalı, yenilikçi yöntem ve teknikleri kullanabilmeli kısacası FeTeMM yaklaşımı farkındalık düzeyleri yüksek olmalıdır. Son yıllarda bilim ve fendeki ilerlemeler ışı̆̆ında fen ve matematik arasındaki etkileşime odaklanıldığında, öğretmenlerimizin sadece uzman oldukları alanda öğretmenlik bilgisine sahip olmalarının ülkemizin ihtiyacı olan insan gücünü yetiştirmede yeterli olmayacağı sonucuna varılmıştır (Çorlu, Capraro ve Capraro, 2014). Öğretmenlerden; eğitim, teknoloji ve uygulamalarında güncel kalabilmek için mesleki organizasyonları, konferans ve bilimsel yayınları takip etmeleri, öğrencileri bilimsel araştırmalara teşvik etmeleri, onların bir ürün ortaya koyabilme, analitik düşünme becerilerinin gelişmesine destek olmaları beklenmektedir. Bu nedenle öğretmenler inovasyon kavramının gerektirdiği, eleştirel düşünme, problem çözme, işbirliği yapma, liderlik yeteneği, esnek düşünce yapısı, uyum sağlayabilme, girişimcilik, sözlü ve yazılı iletişim kurabilme, bilgiye erişebilme ve kullanabilme, merak ve hayal gücü (Wagner, 2008) gibi özelliklere sahip, FeTeMM eğitimi yaklaşımının temel kazanımlarını edinmeleri gerekmektedir. Tüm bu becerilerin kazandırılmasında fen ve matematik derslerinin teorik bilgileri ile mühendislik ve teknolojinin uygulamalarının bütünleşik bir yaklaşımla eğitimcilere kazandırımasının önemli bir yere sahip olduğu söylenebilir. Bu açıdan FeTeMM eğitimi, bir ülkenin kalkınması, bilimsel alanda önderlik edebilmesi ve ekonomik büyümesi için eğitim sistemine dahil edilmesi gereken en önemli unsurlardandır denebilir (Lacey ve Wright, 2009). Son yıllarda yapılan reform çalışmalarının, FeTeMM disiplinlerinin entegrasyonunu benimseyen anlayış ile şekillenmesi (National Academiy of Engineering [NAE], 2010) bu alanlara verilen önemin dikkate değer bir göstergesi niteliğindedir.

Türkiye'de FeTeMM üzerine ilk girişimler üniversiteler bazında gerçekleşmiştir. Diğer taraftan 2014 yılında Milli Eğitim Bakanlığı (MEB) Yenilik ve Eğitim Teknolojileri Genel Müdürlüğü, Avrupa Okul Ağı tarafından yürütülen Scientix Projesi'ne ulusal destek noktası olarak dahil olmuştur. MEB'in 20152019 stratejik planında FeTeMM eğitimine önem verilmesine yönelik hedefler bulunmaktadır. Türkiye Bilimsel ve Teknolojik Araştırma Kurumu'nun (TÜBiTAK) 2011-2016 Bilim Teknoloji Kalkınma Planı, öğrencilerin FeTeMM eğitimini destekleyici bazı faaliyetleri içermektedir (Baran, Canbazoğlu-Bilici, ve Mesutoğlu, 2015). Ancak ülkemizde gerçekleştirilen FeTeMM eğitimine yönelik çalışmalar gelişmiş ülkelerdeki çalışmalara göre henüz başlangıç aşamasındadır. Ülke olarak özellikle öğrenci, öğretmen adayları, öğretmen ve idarecilerin FeTeMM farkındalıklarının yetersiz olduğu sonucu çıkartılabilir. 


\subsection{Araştırmanın Önemi}

FeTeMM eğitiminin gerçek amacına ulaşabilmesi için, sürecin yol göstericisi olan öğretmenlerin bu konuda donanımlı olmaları gerekmektedir. Geleceğin disiplinlerarası problemlerine çözüm üretecek bireyleri yetiştirecek öğretmenler, FeTeMM eğitimi sürecini ve programı çok iyi planlayabilmeli, gerekli materyalleri ve eğitim ortamını hazırlayabilme yetisine sahip olmalıdır. Araştırmalar, FeTeMM konularına olan ilginin ilkokuldan başladığını ve bu nedenle FeTeMM öğretmenlik yetkinliğine sahip ilköğretim öğretmenlerinin hazırlanmasının hayati önem taşıdığını göstermektedir. Örneğin Kaliforniya eyaletinde öğretmenlerin bu ihtiyaçlarını karşılamak için herhangi bir güncellemeye gidilmemiştir (California Comission on Teacher Credentialing [CTC], 2015). Bu yüzdendir ki öğretim progrmlarının öğretmen yetiştirmeye odaklanmamış olması araştırmacıları alternatif öğretim programı geliştirmeye sevketmiştir (Debiase, 2016). Eğitimin bir bütün olması sebebiyle sadece ilkokul değil, ortaokul ve lise düzeyinde de görev yapan öğretmenlerin FeTeMM yaklaşımına olan ilgi, tutum ve farkındalıkları çok önemlidir. Bu noktada sadece öğretmenlerin değil, eğitimin bütün temel öğeleri FeTeMM konusu ile ilgili ve hatta iç içe olmalıdır. DeBiase (2016), yönetim, katıımcı ve öğretmen arasındaki güçlü ve pozitif ilişkiler FeTeMM içeriği, müfredat ve pedagojinin edinimi ve entegrasyonunun başarısına güçlü katkılar sağladığını belirtmiştir. Her kademesi önemli olan eğitimin özellikle ortaokul basamağı, fen, bilişim teknolojileri, matematik, teknoloji tasarım gibi FeTeMM alanına giren derslerin daha ayrıntıı işlenmesinden dolayı FeTeMM kazanımları açısından oldukça önemlidir. FeTeMM alanı öğretmenlerinin bu basamakta FeTeMM kazanımlarını doğrudan veya dolaylı olarak, çocukluk döneminden çıkan ve olgunlaşmaya başlayan ortaokul öğrencilerine aktaracağından bu basamaktaki verilecek eğitim FeTeMM için ayrı bir öneme sahiptir. Bu bağlamda çalışmayla ortaokul öğretmenlerinin FeTeMM farkındalıklarının düzeyi ve öğretmenlerin FeTeMM farkındalıklarını etkileyen değişkenlerin tespit edilmesi ülkemizin FeTeMM yaklaşımındaki bilinç seviyesini göstermesi bakımından önemli olacağı düşünülmektedir.

\subsection{Amaç}

Alanyazın tarandığında ulusal alanda ortaokul FeTeMM alanı öğretmenlerinin FeTeMM farkındalıklarını farklı değişkenler açısından inceleyen çalışmalarla karşılaşıımamıştır. Bu bağlamda çalışmada FeTeMM alanı öğretmenlerin FeTeMM ile ilgili farkındalık düzeylerinin tespiti ve farkındalıklarının farklı değişkenlere göre değerlendirilmesi amaçlanmıştır.

\subsection{Problem}

Bu araştırmada, Türkiye de ortaokullarda görevli fen bilimleri, matematik, teknoloji tasarım ve bilişim teknolojileri öğretmenlerinin farkındalık düzeylerinin ne olduğu ve bu düzeyin farklı değişkenlere göre nasıl değiştiği ana problemi üzerinde durulmuştur. Bu bağlamda;

- Ortaokul öğretmenlerinin FeTeMM farkındalıkları hangi düzeydedir?

- Ortaokul öğretmenlerinin cinsiyet değişkeni açısından FeTeMM farkındalıkları puan ortalamaları arasında anlamlı bir ilişki var mıdır?

- Ortaokul öğretmenlerinin branş değişkeni açısından FeTeMM farkındalıkları puan ortalamaları arasında anlamlı bir ilişki var mıdır?

- Ortaokul öğretmenlerinin öğrenim durumu değişkeni açısından FeTeMM farkındalıkları puan ortalamaları arasında anlamlı bir ilişki var mıdır?

- Ortaokul öğretmenlerinin mezun olduğu fakülte değişkeni açısından FeTeMM farkındalıkları puan ortalamaları arasında anlamlı bir ilişki var mıdır?

- Ortaokul öğretmenlerinin mesleki kıdem değişkeni açısından FeTeMM farkındalıkları puan ortalamaları arasında anlamlı bir ilişki var mıdır? sorularına cevap aranmıştır.

\section{YÖNTEM}

Araştırma nicel araştırma deseni esas alınarak genel tarama modelinde yapılandırılmıştır. Bu modelde, konu olan olay, birey ya da nesne, kendi koşulları içinde ve olduğu gibi tanımlanmaya çalışılır. Herhangi bir şekilde değiştirme, etkileme çabası gösterilmez (Karasar, 2007). 


\subsection{Evren-Örneklem}

Araştırmada seçkisiz olmayan örnekleme yöntemlerinden uygun örnekleme yöntemi benimsenmiştir. Bu kapsamda yapılan araştırmada, Karaman merkeze bağlı ortaokullarda görev yapan 118 fen, matematik ve bilişim öğretmeni çalışma grubunu oluşturmuştur. Çalışma grubu FeTeMM alanı öğretmenleri olması sebebiyle özellikle tercih edilmiştir. Çalışma grubu araştırmaya gönüllü olarak dahil olmuştur. Araştırmaya katılan öğretmenlerin betimsel analizi Tablo 1 de verilmiştir.

Tablo 1. Araştırmaya katılan öğretmenlerin demografik özellikleri

\begin{tabular}{llll}
\hline Bağımsız Değişkenler & Gruplar & $f$ & $\%$ \\
\hline \multirow{3}{*}{ Cinsiyet } & Kadın & 54 & 45.8 \\
& Erkek & 64 & 54.2 \\
\multirow{3}{*}{ Mesleki Kıdem } & $1-5$ & 18 & 15.3 \\
& $6-10$ & 33 & 28 \\
& $11-15$ & 29 & 24.5 \\
Branş & $15-20$ & 21 & 17.8 \\
& 21 ve üzeri & 17 & 14.4 \\
& Fen Bilimleri & 47 & 39.8 \\
Öğrenim Durumu & Matematik & 46 & 39 \\
& Bilişim Tek. & 25 & 21.2 \\
& Önlisans & 3 & 2.5 \\
Mezuniyet & Lisans & 107 & 90.7 \\
& Y.Lisans & 8 & 6.8 \\
& Eğitim Fak & 91 & 77.1 \\
& Fen-Edebiyat Fak. & 26 & 22 \\
\hline
\end{tabular}

Araştırmaya katılan 118 katılımcıdan 54'ü (\%45.8) kadın, 64'ü (\%54.2) ise erkektir. Yine araştırmanın çalışma grubunu oluşturan öğretmenlerin 18'i (\%15.3) 1-5 yıllık mesleki tecrübeye sahip iken, 33'ü (\%28) 6-10 yıllık mesleki kıdeme sahiptir. 29 kişi (\%24.6) 11-15 yıllık, 21'i (\%17.8) 15-20 yıllık ve 17'si (\%14.4) 21 yıl ve üzeri mesleki tecrübeye sahiptir. Araştırmaya katılan öğretmenlerin büyük çoğunluğunun tecrübeli oldukları söylenebilir. Araştırmaya katılan FeTeMM alanı öğretmenlerin branş dağılımları ise şöyledir: 47 kişi (\%39.8) fen bilimleri, 46 kişi (\%39) matematik ve 25 kişi (\%21.2) bilişim teknolojileri branşlarına sahip öğretmenlerdir. Araştırmaya katılan FeTeMM alanı öğretmenlerden 3'ü (\%2.5) ön lisans, 107'si (\%90.7) lisans ve 8'i (\%6.8) yüksek lisans seviyesinde öğrenim durumuna sahiptir. Çalışma grubuna dahil olan öğretmenlerden 91'i (\%77.1) eğitim fakültesi, 26'sı (\%22) fen-edebiyat fakültesi ve 1 kişi (\%0.8) eğitim enstitüsü (Eski Eğitim Fakültesi) mezunudur. Tablo 1' e göre katılımcıların büyük oranda eğitim fakültesi mezunu olduğu görülmektedir. Araştırmaya katılan öğretmenlerin FeTeMM farkındalıklarına ilişkin betimsel veriler Tablo 2' de verilmiştir.

Tablo 2. Katılımcıların FeTeMM Fakındalıkları

\begin{tabular}{llll}
\hline & Gruplar & $\mathrm{f}$ & $\%$ \\
\hline FeTeMM Farkındalı̆̆ı & Evet & 62 & 52.5 \\
& Hayır & 56 & 47.5 \\
\hline
\end{tabular}

Tablo 2' ye göre araştırmaya katılan FeTeMM alanı öğretmenlerinden 62'si (\%52.5) FeTeMM'in farkında olduklarını, 56'sı (\%47.5) ise farkında olmadıklarını dile getirmişlerdir. 


\subsection{Veri Toplama Yöntemi}

Araştırmada veri toplama yöntemi olarak nicel yönteme başvurulmuştur. Nicel veri toplama aracı olarak ise Buyruk ve Korkmaz'ın, 2016) geliştirmiş oldukları 'FeTeMM Farkındalık Ölçeği' kullanılmıştır. Ölçek 5'li likert tipindedir. Ölçek katılımcılara uygulandıktan sonra ölçeğin tekrar geçerlik ve güvenirlik çalışmaları yapılmıştır. Kullanılan ölçeğin kapsam geçerliliği için maddelerin FeTeMM alanı öğretmenlerine uygulanmasında herhangi bir sakınca olup olmadığı FeTeMM alanında çalışmalar yapan iki uzmana sorulmuş ve olumlu dönüt alınmıştır. Yapı geçerliğini test etmek için açımlayıcı faktör analizi (AFA) uygulanmıştır. Bunun hemen öncesinde faktör analizini gerçekleştirebilmek için Bartlett Küresellik Testine ve Kaiser-Mayer-Olkin (KMO) değeri test edilmiştir. Her iki değer (KMO: .915 ve Barlett Sig: .00) maddelerin faktör yüklerini analiz etmenin uygun olduğuna işaret etmiştir (Tablo 3).

Tablo 3. Ölçek maddelerinin KMO ve Barlett's testi sonuçları

\begin{tabular}{lll}
\hline Kaiser-Mayer-Olkin (KMO) Değeri & & .915 \\
\hline \multirow{2}{*}{ Barlett Küresellik Testi } & Ki Kare & 1954.808 \\
& Df & 120 \\
Cronbach Alpha & Sig & .00 \\
& & .88 \\
\hline
\end{tabular}

Veriler üzerinde faktör analizi yapılabilmesi için minimum KMO değerinin .60 olması yeterli görülmektedir (Pallant, 2007). Alanyazın incelendiğinde .45 ve üzerinde faktör yük değerine sahip maddelere ölçekte yer verilmesinin uygun olacağı belirtilmektedir (Büyüköztürk, 2009; Kline, 2000). Bu bağlamda ölçekte yer alan 7. madde çıkartılmıştır. Bunun yanında yapı geçerliliği esnasında 25 derecelik "varimaks" eksen döndürmesi yapılmıştır. Analiz sonuçlarına göre, yapı geçerliği sağlanmış olan maddeler son ölçekte yer almıştır. Ölçek iki alt boyuttan oluşmaktadır. Ölçeğin ilk alt boyutu; 1, 2, 3, 5, 6, 8, 9, 10, 12, 13, 15 ve 16. sorular FeTeMM'e yönelik olumlu bakış açısını ölçerken, 4, 11, 14 ve 17. sorular FeTeMM'e yönelik olumsuz bakış açısını ölçmektedir (Tablo 4).

Tablo 4. Öğretmen anketindeki maddelerin varimax rotasyonuna göre faktör dağılımları ve yükleri

\begin{tabular}{|c|c|c|c|c|c|}
\hline Bölüm & Sorular & Yük Değ. & Bölüm & Sorular & Yük Değ. \\
\hline \multirow{12}{*}{ 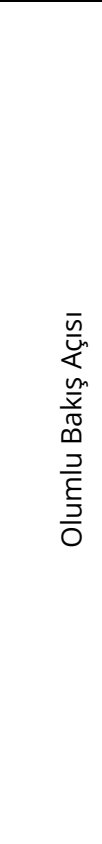 } & S1 & .88 & \multirow{12}{*}{ 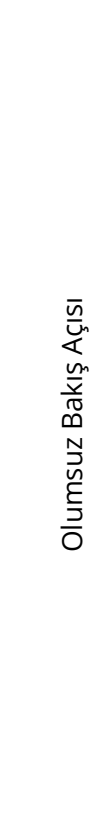 } & S4 & .85 \\
\hline & S2 & .90 & & S11 & .92 \\
\hline & S3 & .88 & & S14 & .81 \\
\hline & S5 & .78 & & S17 & .87 \\
\hline & S6 & .74 & & & \\
\hline & S8 & .92 & & & \\
\hline & S9 & .86 & & & \\
\hline & S10 & .89 & & & \\
\hline & $\mathrm{S} 12$ & .79 & & & \\
\hline & S13 & .80 & & & \\
\hline & S15 & .89 & & & \\
\hline & S16 & .72 & & & \\
\hline
\end{tabular}


Tablo 4'te de görüldüğü üzere olumlu bakış açısı alt faktörünü oluşturuan maddelerin yük değeri .72 ile .92 arasında değişmekte olup, 12 maddeden oluşmaktadır. İkinci alt faktör olan olumsuz bakış açısını oluşturan maddelerin yükü ise .81 ile .92 arasında değişmektedir. Ve bu faktör 5 maddeden oluşmaktadır. Bu iki faktörün toplam varyansın \%74,33'ünü açıkladığı görülmektedir. Alanyazında birden fazla faktörlü ölçeklerde açıklanan varyansın $\% 40$ ile $\% 60$ aralığında olmasının yeterli olacağı belirtilmektedir (Tavşancıl, 2005). Bu bağlamda ölçeğin iki alt boyutu orjinalinde olduğu gibi varyansı ölçeğin tamamı için yeterlidir. Ölçeğin güvenirliğine ise iç tutarlılık katsayısı Cronbach alfa ile bakılmıştır. Bu katsayı .88 olarak hesaplanmıştır. Alanyazında bu değerin .70'in üzerinde olmasının güvenirlik için yeterli olacağı görüşü hakimdir. (Field, 2005).

\subsection{Verilerin Analizi}

Çalışmada kullanılan ölçek, demografik bilgilerin sorulduğu ve farkındalık düzeyini ölçen maddelerin oluşturduğu iki bölümdür. Ölçek ile toplanan verilerin analizine geçmeden önce ölçeğin normallik testi yapılmış çarpıklık ve basıklık değerlerinin $p>+1$ ve $p<-1$ olduğu tespit edilmiştir (Tablo 5).

Tablo 5. FeTeMM Ölçeğinin Boyutlarına Ilişkin Normallik Testi sonuçları

\begin{tabular}{lccccccc}
\hline & \multicolumn{2}{c}{ Kolmogorov-Smirnov } & \multicolumn{2}{c}{ Shapiro-Wilk } & \multicolumn{2}{c}{ Çarpıklık /Basıklık } \\
\hline $\begin{array}{l}\text { Alt } \\
\text { Boyutlar }\end{array}$ & $\begin{array}{c}\text { Kolmogorov- } \\
\text { Smirnov } \\
\text { İstatistiği }\end{array}$ & $\mathrm{sd}$ & $\mathrm{p}$ & $\begin{array}{c}\text { Shapiro-Wilk } \\
\text { İstatistiği }\end{array}$ & $\mathrm{sd}$ & $\mathrm{p}$ & $\mathrm{S} / \mathrm{K}$ \\
\hline Olumlu & .12 & 118 & .00 & .83 & 118 & .00 & $-2.01 / 7.88$ \\
Olumsuz & .13 & 118 & .00 & .92 & 118 & .00 & $.90 / 1.69$ \\
\hline
\end{tabular}

*p>.05, sd: Katılımcı sayısı, S-K: Skewness-Kurtosis değeri, p: Anlamlılık değeri

Tablo $5^{\prime}$ te görüldügü üzere Kolmogorov-Smirnov testi sonuçları da dikkate alınarak ölçeğin iki alt boyutunun puanlarının gruplara göre normal dağılım göstermediği görülmüştür $(p<.05) P<.05$ olması durumunda ilgili değişkenin normal dağılımdan gelmediği söylenir (Can, 2016). Bu bulgular doğrultusunda non- parametrik istatistiksel analiz teknikleri kullanılmasına karar verilmiştir. Ölçeğin iki alt boyutu için Mann-Whitney $U$ testi ve Kruskal-Wallis testi analizleri yapılmıştır. Ölçeğe verilen cevapların aritmetik ortalamaların belirlenmesinde 1.00-1.79 hiç katılmıyorum, 1.80-2.59 katılmıyorum, 2.60-3.39 kararsızım, 3.40-4.19 katılıyorum, 4.20-5.00 tamamen katılıyorum şeklinde bir puan aralığı belirlenmiştir

Tablo 6. Ölçeğin aritmetik ortalamasını yorumlamada kullanılan değerler

\begin{tabular}{lll}
\hline Puan Aralı̆̆ı & Derecelendirilmesi & Yorumlanması \\
\hline $1.00 / 1.79$ & Hiç Katılmıyorum & Çok Az \\
$1.80 / 2.59$ & Katılmıyorum & Az \\
$2.60 / 3.39$ & Kararsızım & Orta \\
$3.40 / 4.19$ & Katılıyorum & Fazla \\
$4.20 / 5.00$ & Tamamen Katılıyorum & Çok Fazla \\
\hline
\end{tabular}

\section{BULGULAR}

\subsection{Ortaokul öğretmenlerinin FeTeMM farkındalıklarına ilişkin bulgular.}

Ortaokul öğretmenlerinin FeTeMM farkındalıklarının alt boyutlara göre puan ortalamaları Tablo 6 da verildiği şekildedir.

Tablo 7. Ortaokul öğretmenleri FeTeMM farkındalıkları ölçeğinin alt boyutlarına ilişkin betimsel veriler

\begin{tabular}{llll}
\hline Alt Boyutlar & $\mathrm{N}$ & $\overline{\boldsymbol{X}}$ & $\mathrm{ss}$ \\
\hline FeTeMM'e ilişkin Olumlu Görüş & 118 & 3.04 & 9.94 \\
FeTeMM'e ilişkin Olumsuz Görüş & 118 & 2.05 & 3.46 \\
\hline
\end{tabular}


Tablo 7 de görüldüğü üzere ölçeğin olumlu alt boyutuna verilen cevapların ortalaması 3.04 tür. Yani ölçeğin FeTeMM'e yönelik olumlu bakış açısını ölçen bu boyutuna katılımcıların orta düzeyde katıldıkları görülmektedir. FeTeMM'e ilişin olumsuz bakış açılasının ölçüldüğü alt boyutun puan ortalaması ise 2.05 tir. Buradan genel olarak katılımcıların FeTeMM'e yönelik olumsuz bakış açılarının düşük bir değere sahip olduğu görülmektedir.

3.2. Ortaokul Öğretmenlerinin Cinsiyet Değişkeni Açısından FeTeMM Farkındalıkları ilişsin Bulgular

Araştırmaya katılan ortaokul öğretmenlerinin cinsiyet değişkenleri bakımından FeTeMM'e yönelik olumlu ve olumsuz alt boyutları arasındaki anlamlılığa ilişkin bulgular Tablo 8'deki gibidir.

Tablo 8. Örneklemdeki öğretmenlerin cinsiyet değişkenine göre ölçeğin alt boyutlarına ilişkin Mann Whitney $\mathrm{U}$ - testi analizi

\begin{tabular}{|c|c|c|c|c|c|c|c|}
\hline & Cinsiyet & $\mathrm{N}$ & Sıra Ortalaması & Sıra Toplamı & Z & $U$ & $p$ \\
\hline \multirow{3}{*}{ Olumlu } & Kadın & 54 & 55.9 & 3018.5 & -1.05 & 1533 & .29 \\
\hline & Erkek & 64 & 62.5 & 4002.5 & & & \\
\hline & Toplam & 118 & & & & & \\
\hline \multirow{3}{*}{ Olumsuz } & Kadın & 54 & 61.8 & 3338 & -.68 & 1603 & .49 \\
\hline & Erkek & 64 & 57.5 & 3683 & & & \\
\hline & Toplam & 118 & & & & & \\
\hline
\end{tabular}

Tablo 8 incelendiğinde, öğretmelerin cinsiyetlerine göre ölçeğin iki alt boyutuna ilişkin toplam puanları arasında Mann Witney $U$ testi ile istatistiksel olarak anlamlı ilişki bulunup bulunmadığı incelenmiş ve herhangi bir anlamlılık bulunamamıştır ( $p>05$ ).

\subsection{Ortaokul Öğretmenlerinin Branş Değişkeni Açısından FeTeMM Farkındalıkları iliş̧kin Bulgular}

Örneklemdeki ortaokul öğretmenlerinin branş değişkenleri bakımından FeTeMM'e yönelik olumlu ve olumsuz alt boyutları arasındaki anlamlılığa ilişkin bulgular Tablo 9'daki gibidir.

Tablo 9. Örneklemdeki öğretmenlerin branş değişkenine göre ölçeğin alt boyutlarına ilişkin Kruskal Wallis testi nalizi

\begin{tabular}{llccccc}
\hline & Branş & N & Sıra Ortalaması & sd & $X^{2}$ & p \\
\hline \multirow{2}{*}{ Olumlu } & Fen B. & 47 & 59.96 & 3 & .137 & .98 \\
& Matematik & 46 & 57.93 & & & \\
& Tek. Tasarım & 1 & 51.50 & & & \\
& Bilişim Tek. & 23 & 59.50 & & & \\
& Toplam & 117 & & & & \\
\hline Olumsuz & Fen B. & 47 & 58.95 & 3 & 2.75 & \\
& Matematik & 46 & 59.64 & & & \\
& Tek. Tasarım & 1 & 112.00 & & & \\
& Bilişim Tek. & 23 & 55.52 & & & \\
& Toplam & 117 & & & & \\
\hline
\end{tabular}

Tablo 9'a göre örneklemdeki öğretmelerin branşlarının, ölçeğin alt boyutlarının toplam puanları arasında istatistiksel olarak anlamlı ilişki bulunamamıştır ( $p>$.05).

\subsection{Ortaokul Öğretmenlerinin Öğrenim Durumu Değişkeni Açısından FeTeMM Farkındalıkları iliş̧kin Bulgular}

Araştırmaya katılan ortaokul öğretmenlerinin öğrenim durumu değişkenleri bakımından FeTeMM'e yönelik olumlu ve olumsuz alt boyutları arasındaki anlamlılığa ilişkin bulgular Tablo 10'daki gibidir. 
Tablo 10. Araştırmaya dahil olan öğretmenlerin öğrenim durumu değişkenine göre ölçeğin alt boyutlarına ilişkin Kruskal Wallis testi

\begin{tabular}{llccllll}
\hline & Öğrenim Durumu & $\mathrm{N}$ & Sıra Ortalaması & $\mathrm{sd}$ & $\mathrm{X}^{2}$ & $\mathrm{p}$ \\
\hline \multirow{3}{*}{ Olumlu } & Önlisans & 3 & 48.67 & 2 & 1.62 & .44 \\
& Lisans & 107 & 58.79 & & & \\
& Y.Lisans & 8 & 73.13 & & & \\
& Toplam & 118 & & & & \\
\hline Olumsuz & Önlisans & 3 & 105.83 & 2 & 6.46 & $.03^{*}$ \\
& Lisans & 107 & 59.02 & & & \\
& Y.Lisans & 8 & 48.50 & & & \\
& Toplam & 118 & & & & \\
\hline
\end{tabular}

$\star \bar{p}<.05$

Tablo $10^{\prime}$ a göre öğretmenlerin öğrenim durumlarının ölçeğin alt boyutlarından olumlu farkındalık boyutunun toplam puanları arasında istatistiksel olarak anlamlı ilişki bulunamamıştır ( $p>.05$ ). Ancak ölçeğin olumsuz yöndeki farkındalık alt boyutunun toplam puanı ile katılımcıların öğrenim durumları arasında anlamlı bir ilişki bulunmaktadır $(p<.05)$. Bu ilişkinin hangi yönde olduğunu bulabilmek için Mann Whitney $U$ testi yapılmıştır. Buna göre ön lisans mezunları ile lisans mezunları arasında ön lisans mezunları lehine (Ön lisans Ort. $=98.17>$ Lisans Ort. $=54.3$ ), ön lisans ile yüksek lisans mezunları arasında ise yine ön lisans mezunları lehine (Ön lisans Ort. = 9.67> Lisans Ort. $=4.63$ anlamlılık vardır. Buradan ön lisans mezunu olup öğretmenlik görevinde bulunan katılımcıların FeTeMM'e ilişkin farkındalıklarının olumsuz yönde olduğu söylenebilir.

\subsection{Ortaokul Öğretmenlerinin Mezuniyet Durumu Değişkeni Açısından FeTeMM Farkındalıkları ilişkin Bulgular}

Örneklemdeki ortaokul öğretmenlerinin mezuniyet durumu değişkenleri bakımından FeTeMM'e yönelik olumlu ve olumsuz alt boyutları arasındaki anlamlılığa ilişkin bulgular Tablo 11'deki gibidir.

Tablo 11. Örneklemdeki öğretmenlerin mezuniyet durumu değişkenine göre ölçeğin alt boyutlarına ilişkin Kruskal Wallis Testi

\begin{tabular}{llcclll}
\hline & Mezuniyet Durumu & $\mathrm{N}$ & Sira Ortalaması & $\mathrm{sd}$ & $\mathrm{X}^{2}$ & $\mathrm{p}$ \\
\hline \multirow{3}{*}{ Olumlu } & Eğitim F. & 91 & 64.09 & 2 & 8.7 & $.01^{*}$ \\
& Fen-Edeb.F. & 26 & 42.44 & & & \\
& Eğitim Enst. & 1 & 85.00 & & & \\
& Toplam & 118 & & & & \\
\hline Olumsuz & Eğitim F. & 91 & 54.26 & 2 & 10.8 & $.00^{*}$ \\
& Fen-Edeb.F. & 26 & 75.67 & & & \\
& Eğitim Enst. & 1 & 115.50 & & & \\
& Toplam & 118 & & & & \\
\hline
\end{tabular}

* $\mathrm{p}<.05$

Tablo 11' e bakıldığında araştırmaya katılan öğretmelerin mezun oldukları okulların ölçeğin alt boyutlarından olumlu farkındalık boyutunun toplam puanları arasında istatistiksel olarak anlamlı ilişki bulunmaktadır $(p<.05)$. Bu ilişkinin hangi yönde olduğunu bulabilmek için Mann Whitney U testi yapılmıştır. Buna göre eğitim fakültesi mezunları ile fen edebiyat fakültesi mezunları arasında eğitim fakültesi mezunları lehine (Eğitim Fak. Ort. $=63.79>$ Fen Edebiyat Fak. Ort. $=42.25$ ) anlamlılık vardır. Bu bulgu dikkate alınarak eğitim fakültesi mezunu öğretmenlerin fen edebiyat fakültesi mezunu öğretmenlere göre FeTeMM farkındalıklarının olumlu yönde olduğu söylenebilir. Ölçeğin FeTeMM farkındalıklarının olumsuz alt boyutunun toplam puanı ile katılımcıların durumları arasında anlamlı bir ilişsi bulunmaktadır $(p<.05)$. Bu ilişkinin hangi yönde olduğunu bulabilmek için Mann Whitney $U$ testi gerçekleştirilmiştir. Testin sonucuna göre eğitim fakültesi mezunları ile fen 
edebiyat fakültesi mezunları arasında fen edebiyat fakültesi mezunları lehine (Fen Edebiyat Fak Fak. Ort. $=75.63>$ Eğitim Fak. Ort. $=54.25$ ), anlamlııı vardır. Bu bulgu dikkate alındığında fen edebiyat mezunu katılımcıların eğitim fakültesi mezunlarına göre FeTeMM farkındalıklarının olumsuz yönde olduğu yorumu yapılabilir.

\subsection{Ortaokul Öğretmenlerinin Mesleki Kıdem Durumu Değişkeni Açısından FeTeMM Farkındalıkları iliş̧kin Bulgular}

Örneklemdeki ortaokul öğretmenlerinin kıdem durumu değişkenine göre FeTeMM'e yönelik olumlu ve olumsuz alt boyutları arasındaki anlamlılı̆g ilişkin bulgular Tablo 12'deki gibidir.

Tablo 12. Örneklemdeki öğretmenlerin mesleki kıdem değişkenine göre ölçeğin alt boyutlarına

\begin{tabular}{|c|c|c|c|c|c|c|}
\hline & Mesleki Kıdem & $\mathrm{N}$ & Sıra Ortalaması & $\mathrm{sd}$ & $x^{2}$ & $p$ \\
\hline \multirow{6}{*}{ Olumlu } & $1-5 \mathrm{yll}$ & 18 & 65.42 & 4 & 14 & $.00 *$ \\
\hline & 6-10 yıl & 33 & 74.09 & & & \\
\hline & $11-15 \mathrm{yll}$ & 29 & 56.76 & & & \\
\hline & $15-20$ yıl & 21 & 52.00 & & & \\
\hline & 21 yıl ve üzeri & 17 & 38.85 & & & \\
\hline & Toplam & 118 & & & & \\
\hline \multirow[t]{6}{*}{ Olumsuz } & $1-5 \mathrm{yll}$ & 18 & 63.67 & 4 & 10.3 & $.03^{*}$ \\
\hline & $6-10 \mathrm{yll}$ & 33 & 44.85 & & & \\
\hline & $11-15 \mathrm{yll}$ & 29 & 61.78 & & & \\
\hline & $15-20 \mathrm{yll}$ & 21 & 63.38 & & & \\
\hline & 21 yıl ve üzeri & 17 & 74.85 & & & \\
\hline & Toplam & 118 & & & & \\
\hline
\end{tabular}

${ }^{*} \mathrm{p}<.05$

Tablo 12' ye göre öğretmelerin mesleki kıdemlerinin ölçeğin alt boyutlarından olumlu farkındalık boyutunun toplam puanları arasında istatistiksel olarak anlamlı ilişki bulunmaktadır $(p<.05)$. Bu ilişkinin hangi yönde olduğunu bulabilmek için Mann Whitney $U$ testi yapılmıştır. Buna göre 6-10 yıllık tecrübeye sahip öğretmenler ile 11-15 yıllık tecrübeye sahip öğretmenler arasında 6-10 yıllık tecrübeye sahip öğretmenler lehine ( 6-10 yıl =35.77 > 11-15 yıl Ort. =26.64) anlamlılık vardır. 6-10 yıllık tecrübeye sahip öğretmenlerle $15-20$ ve 21 yıl ve üzeri mesleki tecrübeye sahip öğretmenler arasında da ise yine 6-10 yıllık tecrübeye sahip öğretmenler lehine (6-10 yıl = 31.45 > 11-15 yıl Ort.= 21.29) anlamlıık vardır. Bulgular dikkate alındığında tecrübeli genç öğretmenlerin FeTeMM e yönelik olumlu farkındalıklarının daha yaşlı ve tecrübeli olan öğretmenlere göre daha yüksek olduğu söylenebilir. Ölçeğin FeTeMM farkındalıklarının olumsuz alt boyutunun toplam puanı ile katılımcıların durumları arasında anlamlı bir ilişki bulunmaktadır. $(p<.05)$. Bu ilişkinin hangi yönde olduğunu bulabilmek için Mann Whitney $U$ testi yapılmıştır. Testin sonucuna göre 6-10 yıllık mesleki kıdeme sahip öğretmenler ile 11-15 yıllık kıdeme sahip öğretmenler arasında 11-15yıllık tecrübeye sahip genç öğretmenler lehine $(11-15 \mathrm{yıl}=36.57>6-10 \mathrm{yıl}$. Ort. $=27.05)$ anlamlılık vardır. Buradan tecrübeli ve daha yaşlı öğretmenlerin FeTeMM e yönelik olumsuz farkındalıkların genç öğretmenlere göre daha yüksek olduğu söylenebilir. Yine 6-10 yıllık tecrübeye sahip öğretmenlerin 16-20 yıllık tecrübeye sahip öğretmenler arasında 16-20 yıllık tecrübeye sahip öğretmenler lehine $(16-20 \mathrm{yıl}=33>6-10 \mathrm{yıl}$. Ort. = 24)anlamlılık vardır. Bu anlamlılık 16-20 yıllık öğretmenler lehinedir. Bu sonuç son yılların yeni yaklaşımı olan FeTeMM'e yönelik tecrübeli ve yaşlı olan öğretmenlerin olumsuz yönde farkındalığa sahip oldukları söylenebilir.

\section{SONUÇ ve TARTIŞMA}

Örneklemdeki öğretmenlerin FeTeMM terimi farkındalıklarına ilşkin sorulan soruya 118 öğretmenden 62'si (\%52.5) duyduklarını, 56'sı (\%47.5) duymadıklarını ifade etmişlerdir. Bu bulguya 
göre ortaokulda görev yapan FeTeMM alanı branşlara sahip öğretmenlerin neredeyse yarısı FeTeMM eğitimine yabancı oldukları söylenebilir. Buradan öğretmenlerin FeTeMM'e yönelik farkındalıklarının arttırıması ve bu konuda bilinçlendirilmelerinin kaçınılmaz olduğu sonucuna ulaşılabilir. Bu sonuç Akaygun ve Aslan-Tutak (2016) Türkiye'deki kimya ve matematik öğretmen adaylarının FeTeMM eğitimine ilişkin bakış açılarının olumlu yönde giderek geliştiği sonucu ile paralellik göstermektedir. Akaygün ve diğ, 2015; Bracey ve Brooks, 2013 yaptıkları çalışmada uygulamalı FeTeMM eğitimine dahil olan öğretmenlerin çalışma sonunda FeTeMM farkındalıklarının, ilgilerinin ve becerilerinin arttığına ilişkin görüş bildirmişlerdir. Öğretmenlerin FeTeMM' e yönelik farkındalıklarının artması aynı zamanda öğrencilerinde FeTeMM'e yönelik ilgi, tutum, mesleki yönelim gibi özelliklerinin üzerinde olumlu bir etkiye sahip olacaktır. (Schmidt ve Kelter, 2017; Christensen ve Knezek, 2017; Gülhan ve Şahin, 2016; Baran, Canbazoğlu Bilici, Mesutoğlu, 2015; Biçer vd, 2015; Gencer, 2015; Yamak, Bulut ve Dündar (2014), Guzey, Harwell ve Moore, 2014; Şahin, Ayar ve Adıgüzel, 2014; Fortus vd., 2004). FeTeMM eğitiminin uygulatıcısı olan öğretmenlerin FeTeMM eğitimi ile ilgili farkındalıklarının ortaya çıkarılması önemlidir çünkü farkındalık olgusu kişilerin ve sosyal toplulukların çevreye karşı bilinçli ve duyarlı olmalarıdır (Keleş, 2007). Bu bilinç ve duyarlılığın artması bilgi ve teknolojinin her saniye hızla değişip geliştiği çă̆ımızda, nitelikli insan gücüne sahip bireylerin matematik ve fen alanlarındaki bilimsel yeterliklere sahip olmalarına da tetikleyecektir.

Örneklemdeki öğretmenlerin FeTeMM'e yönelik farkındalıklarının olumlu yönde ve orta seviyede olduğu söylenebilir. Diğer taraftan öğretmenlerin FeTeMM'e yönelik olumsuz bakış açılarının ise düşük olduğu tespit edilmiştir. Bu bulgu öğretmen adaylarının FeTeMM öğretimine yönelik tutumların olumlu yönde olduğunu vurgulayan çalışmalarla örtüşmektedir ( Adams, Miller, Saul \& Pegg, 2014; Çorlu, Capraro \& Çorlu, 2015). Çalışmanın alt amaçlarından biri olan cinsiyet değişkeni ile FeTeMM farkındalığı arasında herhangi bir anlamlılık olup olmadığına yönelik olarak yapılan analiz sonucu, cinsiyet faktörü ile FeTeMM farkındalığı arasında herhangi bir anlamlılığın bulunmadığını göstermiştir. Yine çalışmanın ikinci alt amacı olarak belirlenen branş değişkeni ile FeTeMM farkındalığı arasındaki anlamlılığa ilişkin olarak örneklemdeki öğretmenlerin branşları ile FeTeMM farkındalıkları arasında herhangi bir anlamlılık bulunmamaktadır. FeTeMM eğitiminin daha etkili bir şekilde uygulanması hususunda FeTeMM alanı öğretmenlerinin, pedagojik bilgilere, branşlarına ve teknolojik pedagojik alana hakim olmaları oldukça önem arz etmektedir (National Research Council NRC, 2012). Çalışmanın dikkat çekici sonuçlarından bir tanesi örneklemdeki öğretmenlerin öğrenim durumları ile FeTeMM farkındalıklarının olumsuz boyutu arasında anlamlılığın bulunmuş olmasıdır. Bu anlamlılık ön lisans mezunları lehinedir. Bu bulgu doğrultusunda lisans ve lisansüstü mezunu öğretmenlerin FeTeMM'e bakış açılarının daha olumlu olduğu çıkarımında bulunulabilir. Öğretmenlerin mezun oldukları okul türü değişkenine göre FeTeMM farkındalıkları arasında ölçeğin iki alt boyutuyla da ilişki vardır. FeTeMM'e yönelik olumlu bakış açılarının eğitim fakültesi mezunları arasında anlamlı bir ilişki bulunurken, FeTeMM'e yönelik olumsuz bakış açılasının fen edebiyat mezunları yönünde olduğu ortaya çıkmıştır. Bu bulgu sınıf öğretmeni adaylarının farklı derslerin öğretimine ilişkin aldıkları dersler (Fen ve Teknoloji Öğretimi I, Fen ve Teknoloji Öğretimi II, Matematik Öğretimi I, Matematik Öğretimi II) ve önemli referans gruplarının (okul müdürü, meslektaşları, üniversite öğretim elemanları) FeTeMM öğretimine yönelik eğilimlerini genel olarak olumlu etkilediği (Akaygün ve Aslan-Tutak, 2016, s. 9) sonucu ile örtüşmektedir. Bu bağlamda eğitim fakültesi mezunlarının FeTeMM eğitimine daha olumlu yaklaştıkları bununda aldıkları eğitimle yakından ilişkili olduğu söylenebilir. Örneklemdeki öğretmenlerin mesleki kıdemleri ile FeTeMM farkındalıkları arasındaki ilişki bağlamında FeTeMM'e yönelik olumlu ve olumsuz bakış açıları arasında anlamlılık vardır. Özellikle 6-10 yıllık tecrübeye sahip öğretmenlerin FeTeMM'e yönelik farkındalıkların olumlu yönde olduğunu söylemek mümkündür. Bu bulgu doğrultusunda tecrübeli genç öğretmenlerin FeTeMM'e yönelik olumlu farkındalıklarının daha yaşlı ve tecrübeli olan öğretmenlere göre daha yüksek olduğu şeklinde bir yoruma gidilebilir. 


\section{5. ÖNERILER}

Çalışmada örneklem grubu olarak FeTeMM alanı ortaokul öğretmenleri yer almıştır. Ancak ülkemizde yeni bir çalışma alanı olan FeTeMM eğitimine yönelik yapılacak çalışmalarda okul öncesinden yükseköğretime kadar bütün kademelerde görevli eğiticilere yer verilmelidir. Yine örneklem grubu okulöncesi, ilkokul ve lise de öğrenim gören öğrencilerin ve velilerin de bulunduğu çalışmalar yapılabilir. Çalışmada ulaşılan eğitim fakültesi mezunu öğretmenlerin FeTeMM farkındalıklarının nedeni bir başka çalışma ile ortaya konulabilir. Benzer şekilde fen fakültesi mezunu olan öğretmenlerin FeTeMM farkındalıklarının olumsuz yönde olmasının sebebi yapılacak çalışmalarda tespit edilebilir. İlerki çalışmalarda sadece FeTeMM alanında çalışan öğretmenler değil, FeTeMM dışındaki özellikle sosyal branşlarda ki öğretmen ve öğretmen adaylarının da FeTeMM farkındalıkları farklı değişkenler açısından incelenebilir. Çalışmada daha yaşlı ve tecrübeli öğretmenlerin FeTeMM farkındalıklarının düşük olma sebebi ve alınması gereken tedbirlere ilişkin ilerki çalışmalarda yer verilebilir. Çalışmada nicel araştırma yöntemleri kullanılmış olup yapılacak çalışmalarda farklı yöntemlere de yer verilebilir. Örneğin yapılacak araştırmalar nicel yöntemin yanında nitel yöntemlerle de desteklenebilir. Karma yöntemlerle çalışma güçlendirilebilir. Çalışmalarda FeTeMM farkındalığı ile farklı değişkenler arasındaki ilişkiyi analiz etmede farklı yöntemlerden de faydalanılabilir. Örneğin normal dağılım gösteren çalışmalarda t-testi, anova, manova, yapısal eşitlik modellemeleri, resgresyon analizi gibi yöntemler kullanılabilir. Yine çalışmada bulunan bağımsız değişkenlerin dışında STEM' e yönelik hizmet içi eğitim ve seminer alma durumları, proje çalışmalarına katılma ve sınıfta farklı öğretim yöntem ve teknikleri kullanma durumları gibi değişkenlerle de çalışmalar gerçekleştirilebilir. Çalışmada öğretmenlerle derinlemesine bilgiler alıp nicel verilerle desteklenerek nitel yöntemler kullanmamak çalışmanın zayıf yönlerinden biridir. Çalışmada nitel yöntemlere yer verilememesinin temel nedeni öğretmenlerin görüşme, mülakat, gözlem gibi nitel veri toplama araçlarının kullanılmasına sıcak bakmamaları olmuştur. Öğretmenlerin yoğun ve tempolu bir çalışma döneminde yapılan bu çalışma daha sakin bir zamanda öğretmenlerle derinlemesine görüşmelerle veya odak grup görüşmeleriyle desteklenebilir. Çalışmanın zayıf yönlerinden bir diğeri ise örneklem grubunun normal dağılım göstermemesinden dolayı yapılan analiz teknikleridir. Bu zayıf yönü güçlendirmek için örneklem grubu sayısının artırılıp, çeşitlendirilmesi gereklidir. 


\section{Kaynakça}

Adams, A. E., Miller, B. G., Saul, M. ve Pegg, J. (2014). Supporting elementary pre-service teachers to teach stem through place-based teaching and learning experiences. Electronic Journal of Science Education, 18(5), 1-22.

Akaygun, S. ve Aslan-Tutak, F. (2016). STEM images revealing stem conceptions of pre-service chemistry and mathematics teachers. International Journal of Education in Mathematics, Science and Technology, 4(1), 56-71. doi:10.18404/ijemst.44833.

Akaygün, S, Aslan-Tutak, F, Bayazıt, N, Demir, K. ve Kesner, J. E. (2015). Kısaca FeTeMM eğitimi: öğretmenler ve öğrencileri için iki günlük çalıştay. 2. International Conference on New Trends in Education, Bahçeşehir Üniversitesi, İstanbul.

Baran, E., Canbazoğlu-Bilici, S. ve Mesutoğlu, C. (2015). Fen, teknoloji, mühendislik ve matematik (FeTeMM) spotu geliştirme etkinliği. Araştırma Temelli Etkinlik Dergisi, 5(2), 60-69).

Biçer, A., Navruz, B., Capraro, R. M., Capraro, M.M., Öner, A. T. ve Boedeker, P. (2015). STEM schools vs. non-STEM schools: comparing students' mathematics growth rate on high-stakes test performance. International Journal on New Trends in Education and Their Implications, 6(1), 138-150.

Bracey, G. ve Brooks, M. (2013). Teachers'n training: Building formal STEM teaching efficacy through informal science teaching experience. ASQ Advancing the STEM Agenda Conference, Grand Valley State University, Michigan.

Buyruk, B. ve Korkmaz, Ö. (2016). FeTeMM farkındalık ölçeği (FFÖ): Geçerlik ve güvenirlik çalışması. Part B: Türk Fen Eğitimi Dergisi, 3(2), 61-76.

Büyüköztürk, Ş. (2009). Sosyal bilimler için veri analizi el kitabı. Ankara: Pegem Akademi Yayıncılık, Ankara.

Can, A. (2016). SPSS ile bilimsel araştırma sürecinde nicel veri analizi. Pegem Akademi Yayıncılık, Ankara.

California Comission on Teacher Credentialing (CTC). (2015). Glossary of terms. Retrieved from: https://www.ctc.ca.gov/glossary/glossary.html. Adresinden 08.11.2017 tarihinde ulaşılmıştır.

Christensen, R. ve Knezek, G. (2017). Relationship of Middle School Student STEM Interest to Career Intent. Journal of Education in Science, Environment and Health. 3(1), 1-13.

Çevik, M. (2017). Ortaöğretim öğretmenlerine yönelik FeTeMM Farkındalık Ölçeği (FFÖ) geliştirme çalışması. International Journal of Human Sciences. 14(3), 2436-2452. Doi: 10.14687/jhs.v14i3.4673

Çorlu, M. S. (2014). FeTeMM eğitimi araştırmaları: Alanda merak edilenler, fırsatlar ve beklentiler [STEM education research: Latest trends, opportunities, and expectations]. Turkish Journal of Educational Research, 3(1), 4-10.

Çorlu, M. S., Capraro, R. M. \& Capraro, M. M. (2014). Introducing STEM education: implications for educating our teachers for the age of innovation. Education and Science, 39(171), 74-85.

Çorlu, S., Capraro, R.M., ve Çorlu, M.A. (2015). Investigating the Mental Readiness of Pre-service Teachers for Integrated Teaching. International Online Journal of Educational Sciences, 7(1), 17. 28

DeBiase, K. (2016). Teacher Preparation in Science, Technology, Engineering, and Mathematics Instruction. Dissertation collection, Department of Educational Leadership, Long Beach California State University.

Derin, G. Yaşin, Ö, Aydin, E., ve Delice, A. (2014). Matematik, fen, ve teknoloji eğitiminin bütünleştirilmesi ölçeğinin Türkiye örneklemine uyarlanması. XI. Ulusal Fen Bilimleri ve Matematik Eğitimi Kongresi. Adana. Türkiye.

Field, A. (2005). Discovering Statistics Using SPSS (2nd. edition). Thousand Oaks, CA: Sage Publications, Inc. 
Fortus, D., Dershimer, R. C., Krajcik, J. S., Marx, R. W. ve Mamlok-Naaman, R. (2004). Design-based science and student learning. Journal of Research in Science Teaching, 41(10), 1081-1110.

Gencer, A. S. (2015). Fen eğitiminde bilim ve mühendislik uygulaması: Fırıldak etkinliği. Araştırma Temelli Etkinlik Dergisi, 5(1), 1-19.

Guzey, S. S, Harwell, M. ve Moore, T. (2014). Development of an instrument to assess attitudes toward Science, Technology, Engineering, and Mathematics (STEM). School Science and Mathematics, 114(6), 271-279.

Gülhan, F. ve Şahin, F. (2016). Fen-teknoloji-mühendislik matematik entegrasyonunun (STEM) 5. Sınıf öğrencilerinin bu alanlarla ilgili algı ve tutumlarına etkisi. International Journal of Human Sciencies. 13(1), 602-620.

Hacıömeroğlu, G. ve Bulut, A.S. (2016). Entegre FeTeMM öğretimi yönelim ölçeği Türkçe formunun geçerlik ve güvenirlik çalışması. Eğitimde Kuram ve Uygulama, 12(3), 654-669.

Keleş, Ö. (2007). Sürdürülebilir yaşama yönelik çevre eğitimi aracı olarak ekolojik ayak izinin uygulanması ve değerlendirilmesi, Yayınlanmamış Doktora Tezi, Gazi Üniversitesi Eğitim Bilimleri Enstitüsü, Ankara.

Karasar, N. (2007). Bilimsel araştırma yöntemi. Ankara: Nobel Yayın Dağıtım.

Kline, P. (2000). The Handbook of Psychological Testing (2nd Edition). London and Newyork: Routledge.

Koyunlu Ünlü, Z., Dokme, I. ve Ünlü, V. (2016). Adaptation of the science, technology, engineering, and mathematics career interest survey (STEM-CIS) into Turkish. Eurasian Journal of Educational Research, 63, 21-36, http://dx.doi.org/ 10.14689/ejer.2016.63.2

Lacey, T. A. ve Wright, B. (2009). Occupational employment projections to 2018. Montly Labor Review, November, 82-109.

M.E.B. (2015). Millî Eğitim Bakanlığı 2015-2019 Stratejik Planı. http://sgb.meb.gov.tr/meb_iys_dosyalar/2015_09/10052958_10.09.2015sp17.15imzasz.pdf adresinden 08.08.2017 tarihinde erişilmiştir.

Moore, T. J., Stohlmann, M.S., Wang, H.-H., Tank, K.M., Glancy, A.W. ve Roehrig, G. H. (2014). Implementation and integration of engineering in K-12 STEM education. In Ş. Purzer, J. Strobel, \& M. Cardella (Eds.), Engineering in precollege settings: Research into practice (pp. 35-60). West Lafayette: Purdue Press.

National Academy of Engineering [NAE]. (2010). Standards for K-12 engineering education. Washington, DC: National Academies Press.

National Research Council [NRC]. (2012). A Framework for k-12 science education: practices, crosscutting concepts, and core ideas. Washington DC: The National Academic Press.

Pallant, J. (2007). SPSS Survival Manual: A Step-By-Step Guide to Data Analysis Using SPSS for Windows. Philadelphia, PA: Open University Press.

Schmidt, K. M. ve Kelter, P. (2017). Science Fairs: A Qualitative Study of Their Impact on Student Science Inquiry Learning and Attitudes toward STEM. Science Educator, 25 (2), 126-132.

Şahin, A., Ayar, M. C. ve Adıgüzel, T. (2014). Fen, teknoloji, mühendislik ve matematik içerikli okulsonrası etkinlikler ve öğrenciler üzerindeki etkileri. Kuram ve Uygulamada Eğitim Bilimleri. $14(1), 1-26$.

Tavşancıl, E. (2005). Tutumların ölçülmesi ve SPSS ile veri analizi. Ankara: Nobel.

Wagner, T. (2008). Rigor redefined. Educational Leadership, 66(2),20-24.

Yamak, H., Bulut, N. ve Dündar, S. (2014). 5. Sınıf öğrencilerinin bilimsel süreç becerileri ile fene karşı tutumlarına FeTeMM etkinliklerinin etkisi. Gazi Üniversitesi Gazi Eğitim Fakültesi Dergisi, $34(2), 249-265$. 


\section{Extended Summary}

The new approach, briefly called STEM which takes science, technology, engineering and mathematics as a whole, occupies an important position in the education of science literate individuals who are lifelong learners with the awareness of sustainable development, equipped with 21st century skills, acquired creative problem-solving skills fulfilling their duties in the real world. STEM area teachers are expected to have technological pedagogical field knowledge, use innovative methods and techniques, in short to have high awareness of the STEM approach awareness. In recent years, it was reached as a result that the fact that the teachers are only experts in their teaching fields would not be enough to raise the human power that the society needs when focusing on the interaction between science and mathematics in the light of developments in science (Çorlu, Capraro \& Capraro, 2014). Therefore teachers are required to acquire the key outcomes of STEM education having features such as critical thinking, problem solving, cooperation, leadership, flexible thinking, adaptability, entrepreneurship, verbal and written communication, accessing and using information, curiosity and imagination (Wagner, 2008) required by the concept of innovation and its action. Teachers who are the leading guides of the process, required to be equipped in this regard in order to achieve the real goal of the STEM education. Teachers who will educate individuals who would produce a multidisciplinary solution to the multidisciplinary problems of the future should be able to plan the STEM education process and program and prepare the necessary materials and teaching environment. Studies indicate that the interest in STEM topics begins in primary schools and for this reason the preparation of primary schools with STEM education competence is vital (DeBiase, Kirstie 2016). Because of the fact that education is integrated, the interest, attitudes and awareness of the teachers who work not only in primary schools but also in secondary and high schools are very important for the STEM approach. Secondary education is very important as the STEM disciplines begin to evolve with sharp lines in terms of STEM achievements. Particularly secondary school teachers have a separate prescription, as they would transfer STEM achievements to secondary school students who are leaving childhood and beginning to mature. In this context, understanding the STEM awareness of secondary school teachers and the variables that affect this awareness would contribute to the rapid spread of the STEM approach in Turkey in particular. The aim of this study is to identify awareness levels of science, mathematics, technology and design and information technologies teachers in secondary schools in Turkey according to various variables. In this context;

- What are the STEM awareness levels of secondary school teachers?

- Is there a significant correlation between the mean scores of STEM awareness of secondary school teachers in terms of gender variable?

- Is there a significant correlation between mean scores of STEM awareness of secondary school teachers in terms of branch variable?

- Is there a significant correlation between mean scores of STEM awareness of secondary school teachers in terms of educational background variable?

- Is there a significant correlation between mean scores of STEM awareness of secondary school teachers in terms of graduated faculty variable?

- Is there a significant correlation between mean scores of STEM awareness of secondary school teachers in terms of professional seniority variable?

The study was structured in the survey model based on quantitative research design. Survey models are research approaches that aim to describe the past and the present as it exists. The event, individual or the object that is subject to research is tried to be defined within its own conditions. No effort is made to alter or influence them in any way (Karasar, 2007). In this study, an appropriate sampling method among non-random sampling methods was adopted. in this context, the sample of the study consisted of 118 science, mathematics and information technologies teachers working in secondary schools in Karaman. The study was especially 
preferred as they are teachers of the STEM field. The study group was voluntarily involved in the study. The 'STEM Awareness Scale' developed by Buyruk and Korkmaz (2016) was used as the data collection tool. The scale is of the 5 likert-type. The validity and reliability studies were performed again after the scale was applied to the participants.

Of the 118 secondary school teachers who participated in the study, $54(45.8 \%)$ were female and $64(54.2 \%)$ were male. It can be said that the study group has a homogeneous distribution in terms of gender variable. Furthermore, $18(15.3 \%)$ of the teachers participated in the research had 1-5 years, $33(28 \%)$ of them had 6-10 years, $29(24.6 \%)$ of them had 11-15 years, 21 (17.8) of them had $15-20$ years and 17 of them (14.4\%) had over 21 years professional seniority. In terms of branch distribution, 47 (39.8\%) participants were science teachers, 46 (39\%) were mathematics teachers and $24(20.3 \%)$ were information technologies teachers. $3(2.5 \%)$ of the STEM teachers involved in the study had a foundation degree, 107 (90.7\%) participants had a bachelor's degree and $8(6.8 \%)$ participants had a postgraduate degree. 91 (77.1\%) of these teachers graduated from the education faculty, 26 (22\%) teachers graduated from the faculty of science and literature and 1 $(0.8 \%)$ teacher graduated from the education institution. 62 (52.5\%) of the 118 teachers included in the study expressed that they did not hear STEM terms while 56 (47.5\%) participants indicated that they did. According to this finding, it can be said that almost half of the participants with STEM field braches working in secondary schools are unfamiliar with STEM education. It can be said that teachers' awareness of STEM involved in the study is positively and moderately in terms of arithmetic mean. One of the sub-goals of the study is to investigating if there is a significant relation between gender variable and STEM awareness and the analyzes carried out in this respect indicate that there is no significant relationship between gender factor and STEM awareness. Furthermore, there is no significant difference between branch variable and STEM awareness, which was the second sub-goal of the study. Significance was found between educational backgrounds of teachers participating in the study and negative dimension of STEM awareness. This significance is in favor of foundation degree graduates. It can be said with this finding that the views of teachers with bachelor's degree and graduate degree for STEM are more positive. On the contrary, it seems that the views of teachers with foundation degree for STEM are more negative. There is also relationship between STEM awareness and two sub-dimensions of the scale in terms of school types in which teachers graduated. While a positive relation was found between education faculty graduates for positive aspects towards STEM, it was revealed that negative views towards STEM were in the direction of science and literature graduates. This finding leads to conclusion that education faculty graduates are more likely to approach STEM education and this is closely related to the education they received. There is a significant difference between positive and negative views for STEM when looking at the relationship between STEM awareness and professional seniority of teachers participating in the research. Especially it is possible to say that teachers with 6-10 years of experience have a positive attitude towards STEM. It can be said that positive awareness of the young teachers who are experienced towards STEM is higher than the older and experienced teachers.

This study was conducted to investigate the relationship between STEM awareness of secondary school teachers and various variables. Secondary school teachers were included in the study. However, teachers in all stages from pre-school to higher education should be includes as participants in STEM education, which is a new research area in Turkey. Likewise, the sample group can be carried out with pre-school, primary school and high school students and their parents. Furthermore, studies can be carried out for the awareness of teacher candidates. Not only STEM awareness of teachers in STEM field but also teachers and teacher candidates, especially those in social studies other than STEM can be examined in terms of different variables in future studies. Quantitative research methods were used in the study and different study methods can be included in different studies. For instance, studies can be supported by quantitative methods as well as quantitative methods. Studies can be strengthened by mixed methods. Different methods can also be used to analyze the relationship between STEM awareness and different variables in 
future studies. For instance, t-test, anova, manova, structural equation models and regression analysis can be used in studies with normal distribution. In addition, studies can be carried out variables such as in-service training and seminars for STEM, participating in projects, the use of different teaching methods and techniques, apart from the independent variables used in the study.

The main drawback of this study is to not presenting the findings received from in-depth information supported with quantitative data. The reason why qualitative methods could not be included in the study was that the teachers were not interested in the use of qualitative data collection tools such as interviews and observations. Research carried out during a busy period can be repeated by conducting in-depth interviews with teachers at a calmer time. Another weak point of the study is the use of nonparametric analysis techniques as the study group did not indicate normal distribution. The number of participants can be increased and diversified to avoid this. In this way, studies with a stronger scientific basis can be put forward with a sample group with normal distrubtion through parametric analyzes. 